\title{
UNIVERSUM
}

\section{AMÉRICA LATINA: UNA INTERPRETACIÓN PARA EXPLICAR LA NUEVA RELACIÓN CENTRO-PERIFERIA CON CHINA}

Latin America: an interpretation to explain the new core-peripheral relationship with China

\section{Raúl Bernal-Meza' (iD)}

'Universidad Arturo Prat, Instituto de Estudios Internacionales, Iquique, Chile. Doctor en Sociología, Pontificia Universidad Católica Argentina: Buenos Aires, Argentina.

\section{RESUMEN}

A partir del análisis de publicaciones recientes, investigaciones, estudios de campo y datos estadísticos sobre las relaciones económicas entre China y América Latina, se sostiene que estas se caracterizan por una estructura de relaciones centro-periferia, que se ha desarrollado en unas pocas décadas. El texto ofrece una explicación e interpretación sobre dicha morfología y brinda un diagnóstico sobre la evolución y prospectiva de esas relaciones.

PALABRAS CLAVE: China; América Latina; centro-periferia.

\section{ABSTRACT}

From the analysis of recent publications, research, field studies and statistical data on the economic relations between China and Latin America, it is argued that these are characterized by a structure of core-periphery relations, which has developed in a few decades. The text offers an explanation and interpretation of this morphology, and provides a diagnosis of the evolution and prospect of these bilateral relations.

KEYWORDS: China; Latin America; core-periphery. 


\section{INTRODUCCIÓN}

La modelización "centro-periferia", con la cual Prebisch (1949; 1951) identificó los dos segmentos en que se dividían los países por su estructura económica se completó con el surgimiento de una categoría intermedia, "semi-periferia", que caracterizaría a ciertas sociedades por la presencia de grandes mercados internos, importantes clases medias y relativo progreso en el desarrollo industrial.

Las relaciones económicas entre China y América Latina se desarrollan en la fase del capitalismo histórico, identificada como globalización/mundialización (Bernal-Meza, 1996), que corresponde al período de lo que Polanyi (1944) llamó la gran transformación en la historia mundial: el surgimiento del capitalismo de mercado bajo diferentes variedades del capitalismo. China representaría el modelo más exitoso y Brasil el único latinoamericano del grupo de modelos alternativos a los ejemplos anglosajón, renano y japonés (Becker, 2013). La decadencia del desarrollo industrial y tecnológico detuvo su espiral de crecimiento, manteniéndolo en la semi-periferia económica y de "periferia" en relación a China (Bernal-Meza, 2019). Li y Shaw (2013) aplicaron la interpretación de Polanyi al análisis de las relaciones entre China y África, para explicar la relación centro-periferia, de carácter imperialista, que no se da en el caso latinoamericano. Sin embargo, ella ayuda a comprender la relación con América Latina porque esta es parte de la periferia china y quizás su segmento más importante, por las características de Sudamérica: presencia de dos economías intermedias Brasil y Argentina que desde las primeras décadas del siglo XX habían avanzado hacia la semi-periferia gracias a sus procesos de industrialización-; grandes mercados de consumo Brasil, Colombia y Argentina-; reservorio de minerales estratégicos (cobre, litio), alimentos (soja, carnes) y otros recursos naturales (energía, hierro, agua; riquezas ictícolas), etc.

\section{LA EXPANSIÓN DE LA PRESENCIA CHINA}

El crecimiento económico chino en América Latina es parte de su expansión en la economía mundial y las características de las relaciones obedecen a la configuración de un patrón de especialización productiva. El proceso de periferarización y re-periferización que sufre nuestra región, como consecuencia de los efectos de economía política internacional causados por el extraordinario crecimiento y desarrollo económico, industrial y tecnológico alcanzados por China en tan solo treinta años, ha motivado diversos que citamos en adelante. La periferizarización corresponde a la

${ }^{\mathrm{I}}$ Cfr. Prebisch, Furtado, Ferrer, Wallerstein y Arrighi. 
continuidad de la condición de atraso de aquellas economías que habían hecho progresos para abandonar la situación periférica, con procesos de industrialización primaria, que regresaron al estadio anterior como consecuencia de la especialización productiva; mientras que la reperiferización de las economías más industrializadas - Brasil y Argentina- es el retorno a una condición primaria que ya había sido abandonada. Ambas situaciones, puestas contra el telón de fondo del desarrollo económico y exportador de China ponen de relevancia el contraste entre el alto desarrollo que ha logrado la potencia y las dificultades de los países latinoamericanos por reducir su atraso y dependencia respecto de las economías más dinámicas del capitalismo mundial, manteniéndose con las características históricas: exportadora neta de productos primarios y commodities. Si bien ha habido un modesto progreso en el crecimiento de las exportaciones industriales, en el caso del intercambio con China esta participación se reduce considerablemente (CEPAL, 20I8).

\section{CARACTERÍSTICAS DEL COMERCIO CHINO-LATINOAMERICANO}

La especialización es la característica más preocupante en el intercambio comercial con China. El diagnóstico de la CEPAL señala que "La canasta de exportaciones de América Latina y el Caribe hacia China es mucho menos sofisticada que sus envíos hacia el resto del mundo. En 2016 los productos primarios representaron el $72 \%$ del valor de las exportaciones de la región a China, frente a un $27 \%$ en el caso de sus envíos al resto del mundo. Por el contrario, las manufacturas de tecnología baja, media y alta representaron solo un $8 \%$ de las exportaciones regionales a China, frente a un $57 \%$ de los envíos al resto del mundo. Lo contrario ocurre en el caso de las importaciones: mientras que las manufacturas de baja, media y alta tecnología representaron en 2016 el 91\% del valor de las compras regionales desde China, su participación en las importaciones desde el resto del mundo, aunque también elevada, fue sustancialmente menor (68\%)" (2018: 4I). El comercio es netamente inter-industrial: materias primas por manufacturas; similar diagnóstico que se había hecho en 2015. Para 2016, solo cinco productos, todos básicos, representaron el 70\% del valor de los envíos de la región a China. La lista de los zo productos principales exportados a ese país se compone casi exclusivamente de minería, hidrocarburos, y algunos productos agropecuarios y forestales. Los únicos bienes industriales son las cajas de cambio y los automóviles, que representan solo el I\% del valor de los envíos (CEPAL, 20I8: 42). Ver Tabla I. 


\begin{tabular}{|c|c|c|c|c|}
\hline Posición & $\begin{array}{l}\text { Código del Sistema } \\
\text { Armonizado de Designación y } \\
\text { Codificación de Mercancías }\end{array}$ & Descripción & $\begin{array}{c}\text { Monto } \\
\text { (en millones de dólares) }\end{array}$ & $\begin{array}{l}\text { Participación } \\
\text { (en porcentajes) }\end{array}$ \\
\hline I & I20190 & Porotos de soja & I7 328 & $2 \mathrm{I}, 8$ \\
\hline 2 & 260300 & $\begin{array}{l}\text { Minerales de cobre y sus } \\
\text { concentrados }\end{array}$ & I2 439 & I5,6 \\
\hline 3 & 260III & $\begin{array}{l}\text { Minerales de hierro y sus } \\
\text { concentrados }\end{array}$ & IO 203 & $\mathrm{I} 2,8$ \\
\hline 4 & 7403II & $\begin{array}{l}\text { Cobre refinado (cátodos de } \\
\text { cobre) }\end{array}$ & $837 \mathrm{I}$ & IO, 5 \\
\hline 5 & 270900 & Petróleo & 7038 & 8,8 \\
\hline 6 & 470329 & $\begin{array}{l}\text { Pasta química, de madera } \\
\text { distinta de la de coníferas }\end{array}$ & 2025 & 2,5 \\
\hline 7 & 020230 & $\begin{array}{l}\text { Carne deshuesada, de } \\
\text { bovinos, congelada }\end{array}$ & I 353 & $\mathrm{I}, 7$ \\
\hline 8 & 740200 & $\begin{array}{l}\text { Cobre sin refinar; ánodos } \\
\text { de cobre para refinado } \\
\text { electrolítico }\end{array}$ & I I 25 & $\mathrm{I}, 4$ \\
\hline 9 & O2O7I4 & $\begin{array}{l}\text { Trozos y despojos } \\
\text { comestibles, de gallo o de } \\
\text { gallina, congelados }\end{array}$ & 998 & $\mathrm{I}, 3$ \\
\hline IO & 230120 & $\begin{array}{l}\text { Harina, polvo y pellets, de } \\
\text { pescado o de crustáceos }\end{array}$ & $9 \mathrm{I} 7$ & $\mathrm{I}, 2$ \\
\hline II & $47032 \mathrm{I}$ & $\begin{array}{l}\text { Pasta química, de madera } \\
\text { de coníferas }\end{array}$ & 868 & $\mathrm{I}, \mathrm{I}$ \\
\hline I 2 & I7OII4 & Azúcar de caña en bruto & 827 & $\mathrm{I}, \mathrm{O}$ \\
\hline I3 & 080929 & Cerezas, frescas & $67 \mathrm{I}$ & 0,8 \\
\hline I4 & 26I6Iо & $\begin{array}{l}\text { Minerales de plata y sus } \\
\text { concentrados }\end{array}$ & 585 & 0,7 \\
\hline I5 & 271019 & $\begin{array}{l}\text { Aceites medios y } \\
\text { preparaciones, de petróleo } \\
\text { o de mineral bituminoso }\end{array}$ & 584 & 0,7 \\
\hline 16 & 740400 & $\begin{array}{l}\text { Desperdicios y desechos, } \\
\text { de cobre }\end{array}$ & 573 & 0,7 \\
\hline I7 & 260700 & $\begin{array}{l}\text { Minerales de plomo y sus } \\
\text { concentrados }\end{array}$ & $44 \mathrm{I}$ & 0,6 \\
\hline I8 & 260800 & $\begin{array}{l}\text { Minerales de cinc y sus } \\
\text { concentrados }\end{array}$ & 425 & 0,5 \\
\hline I9 & 870840 & $\begin{array}{l}\text { Cajas de cambio para } \\
\text { tractores, automóviles para } \\
\text { más de io personas }\end{array}$ & 403 & 0,5 \\
\hline \multirow[t]{3}{*}{20} & 870323 & Automóviles de turismo & 381 & 0,5 \\
\hline & & $\begin{array}{l}\text { Total de los } 20 \\
\text { principales productos }\end{array}$ & 67554 & 84,8 \\
\hline & & Total exportado & 79636 & $\mathrm{IOO}, \mathrm{O}$ \\
\hline
\end{tabular}

China ha generado una estructura de relaciones económicas internacionales —siendo Argentina uno de los más graves ejemplos- que hace a los países sudamericanos depender crecientemente de ella en comercio, inversiones y préstamos. Esta situación tiene un impacto negativo sobre las estrategias de integración de América del Sur, porque China sustituye a los socios sudamericanos de industrialización intermedia (Dussel 2016; Oviedo, 20I6; Beckerman y 
Moncaut, 2016). La armonía de los intereses comerciales, entre exportaciones primarias (soja, minerales, petróleo) e importaciones industriales, creó una relación comercial de intercambios intersectoriales que fue el origen de la compleja situación económica y financiera existente en los países con déficit comercial bilateral y de la primerización exportadora de las economías que aún mantienen superávits comerciales con China, como Brasil, Chile y Venezuela; cada una de ellas especializada en determinados commodities.

Según análisis de CEPAL (2018: 39), en 2017 el valor del comercio de bienes entre la región y China creció un i6\%, acercándose a los 266.000 millones de dólares. Esta cifra fue ligeramente inferior al máximo histórico de 268.ooo millones de dólares, alcanzado en 20iz. Ver Gráfico I.

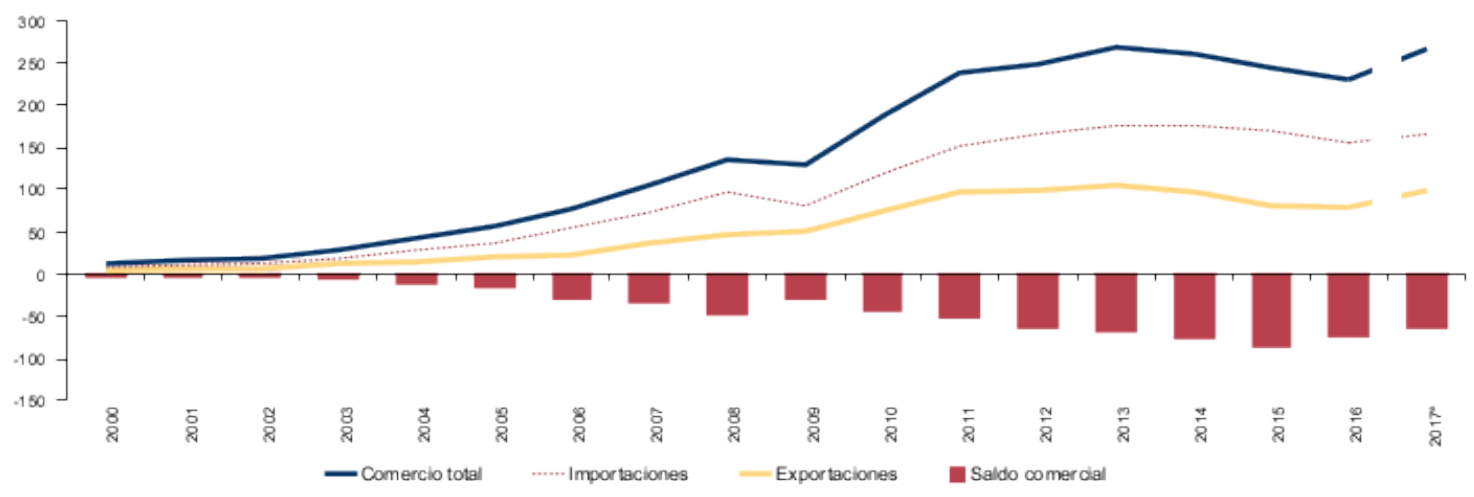

GRÁFICO I: América Latina y el Caribe: comercio de bienes con China, 2000-2017. (En miles de millones de dólares) (Fuente: CEPAL, 20I8, p. 39)

\section{DOS EJEMPLOS DE ECONOMÍAS EN PROCESO DE RE- PERIFERIZACIÓN CON CHINA: BRASIL Y ARGENTINA}

Brasil y Argentina - las dos economías industriales de América del Sur- tienen asociaciones estratégicas con China. Si bien Brasil tiene intereses políticos globales dentro del sistema internacional, tales los desarrollados en el marco de los BRICS, que Argentina no tiene, ninguno ha logrado llevar esa relación a un equilibrio intra-industrial de los intercambios comerciales. Como señala Becard (2017: 405), las relaciones entre China y Brasil no se caracterizan por una asociación estratégica horizontal y recíproca basada en el intercambio balanceado de productos y servicios y cooperación en áreas fundamentales del proyecto de desarrollo de Brasil. A nivel multilateral, la relación, en el marco de BRICS, reprodujo la relación centro-periferia y esta situación ha debilitado a BRICS, porque reproduce internamente una relación norte-sur y centro-periferia que el mismo agrupamiento cuestiona a nivel de la economía política internacional, y ha debilitado el objetivo del multilateralismo de la política exterior brasileña (Bernal-Meza, 20ı9). Becard et.al. 
(2019: I44) señalan “...Beijing is so powerful that Brasilia is increasingly worried about Brazil's dependence on Chinese trade and investments [...] So the question for the future is: will loyalty increase in this path of growing Brazilian dependency?". Para Bernal-Meza (2019:I25) "Brazil went to BRICS looking for a strategic alliance with China in the field of international politics and economy, but it did not succeed" y la razón ha sido la relación centro-periferia que se desarrolló entre ambos. Por su parte, China y Argentina representan dos modelos opuestos de desarrollo capitalista: el exitoso modelo exo-orientado chino y el fracasado modelo argentino de desarrollo por sustitución de importaciones ( $\mathrm{Li}, 2019$; Oviedo, 2012), que como todos los procesos similares de América Latina no logró insertarse dinámicamente en una economía mundial dominada por el desarrollo científico-tecnológico (Dussel, 2016; Bekerman y Moncaut, 2016; Sevares, 2015). El choque de modernizaciones, el atraso tecnológico y la especialización confluyeron para conducir a Argentina a lo que Oviedo (2016: 275) denominó "la paradoja de los alimentos": siendo Argentina un productor de materias primas alimenticias demandadas por China, beneficiada por el alza del precio mundial de los commodities, entre 2008 y 2014 transfirió más de U\$S 24.000 millones mediante déficit comercial a China, un país con necesidad creciente de importar alimentos. Es decir, la lógica parecía no funcionar en el comercio argentino-chino.

Brasil y Argentina tienen una estructura exportadora articulada a las cadenas productivas y de consumo chinas, pero no a sus propias estructuras productivas. El comercio bilateral BrasilChina es el más importante de América Latina. Según datos de Comexstat ${ }^{2}$, las exportaciones brasileñas en 2019, fueron de US\$ 62,871.652,IO7 (FOB), mientras que las importaciones sumaron US \$ 35.270.400.750, sobre un total de exportaciones brasileñas al mundo por US\$223,998,669,052 (FOB) y de importaciones del mundo por US\$ 177,34I,225,208 (FOB). Se trata de un crecimiento muy importante de las exportaciones brasileñas, pero que sin embargo se caracterizan por su condición primaria, principalmente mineral de hierro y soja. Según datos del Instituto Brasileño de Economía de la Fundación Getulio Vargas (FGV), divulgados por la Agência Brasil China continuó siendo el principal destino de las exportaciones brasileñas en 2018 y principal responsable del superávit de US $\$ 58,700$ millones en transacciones comerciales con el exterior ese año. Aunque menor que en 2017, cuando el superávit cerró en US\$ 67,000 millones, el de 2018 fue el segundo valor más alto en la serie histórica de la balanza comercial brasileña. La FGV informó que el aumento de la participación china entre 2017 y 2018 - del 21,8\% al 26,8\% - fue impulsada por los tres principales productos básicos exportados a ese país: soja en grano, petróleo crudo y mineral de 
hierro. En conjunto representan el 82\% de las exportaciones brasileñas a China ${ }^{4}$. El carácter interindustrial del comercio bilateral se observa al analizar la canasta de importaciones. Ver Tabla 2.

TABLA 2: Brasil-China: Productos importación (Valor del comercio en miles de US\$)

\begin{tabular}{|l|l|}
\hline Grupos de Productos & \multicolumn{1}{|c|}{ Año 20I8 } \\
\hline Todos los productos & $34 \cdot 730.024,9 \mathrm{I}$ \\
\hline Bienes de capital & I8.090.865,02 \\
\hline Maquinaria y electricidad & I4.I42.053,94 \\
\hline Bienes intermedios & $9 \cdot 360.401,23$ \\
\hline Bienes de consumo & $6.912 .847,58$ \\
\hline Productos químicos & $4.939 \cdot 408,68$ \\
\hline Transporte & $4 \cdot 777 \cdot 546,30$ \\
\hline Textiles y prendas de vestir & $2.918 .419,55$ \\
\hline Metales & $2.357 \cdot 774,24$ \\
\hline Varios & $2.095 \cdot 979,04$ \\
\hline Plástico o caucho & I.485.992,27 \\
\hline Piedras y vidrio & $445 \cdot 947,74$ \\
\hline Materias primas & $365 \cdot 908,27$ \\
\hline Cueros y pieles & $334 \cdot 991,44$ \\
\hline Combustibles & $279 \cdot 724,83$ \\
\hline Madera & $249 \cdot 991,49$ \\
\hline Reino animal & $239.212,54$ \\
\hline Calzado & I72.070,79 \\
\hline Reino vegetal & I32.848,94 \\
\hline Productos alimenticios & I24.723,79 \\
\hline Minerales & $33 \cdot 339,34$ \\
\hline
\end{tabular}

(Fuente: WITS)

China se acercó a América Latina, y particularmente a Argentina, buscando recursos para sostener su proceso interno de urbanización e industrialización en el largo plazo. El crecimiento chino tuvo gran impacto en la estructura económica argentina y la composición de su canasta de exportaciones. Bernal-Meza y Zanabria (2020) concluyeron en su análisis y coincidieron con Oviedo (2016) en que siendo Argentina la tercera economía más industrializada de América Latina, su comercio con China era el que tenía el perfil más primario de todo el comercio argentino de exportaciones; es decir, basado en la exportación de productos básicos o commodities. Ese comercio bilateral era parte de un esquema centro-periferia mayor, extendido a toda América Latina, como señalaron Bernal-Meza y Li (2020), Dussel (2016), Oviedo (2016) y CEPAL (2018; 2015).

4 https://cutt.ly/AmPYgb3 
Las exportaciones se estancaron desde 2008, y Argentina inició una balanza bilateral crecientemente negativa, debido a la importación de productos industriales. Al final del gobierno de Cristina Fernández (2015), el balance financiero mostró que Argentina transfirió US\$ 30,815 millones a través del déficit comercial a China entre 2008 y 2015, debido a unos US\$ 8,ooo millones (más intereses) por el acuerdo de canje de monedas (swaps) y el pago de los préstamos para inversiones en ferrocarriles e infraestructura (Oviedo, 2016; Sevares, 2015). A pesar de que la economía argentina es un mercado protegido, excluyendo al MERCOSUR, en septiembre de 2019 China desplazó a Brasil - beneficiario del arancel externo común- como principal socio comercial. Ver Gráfico 2.

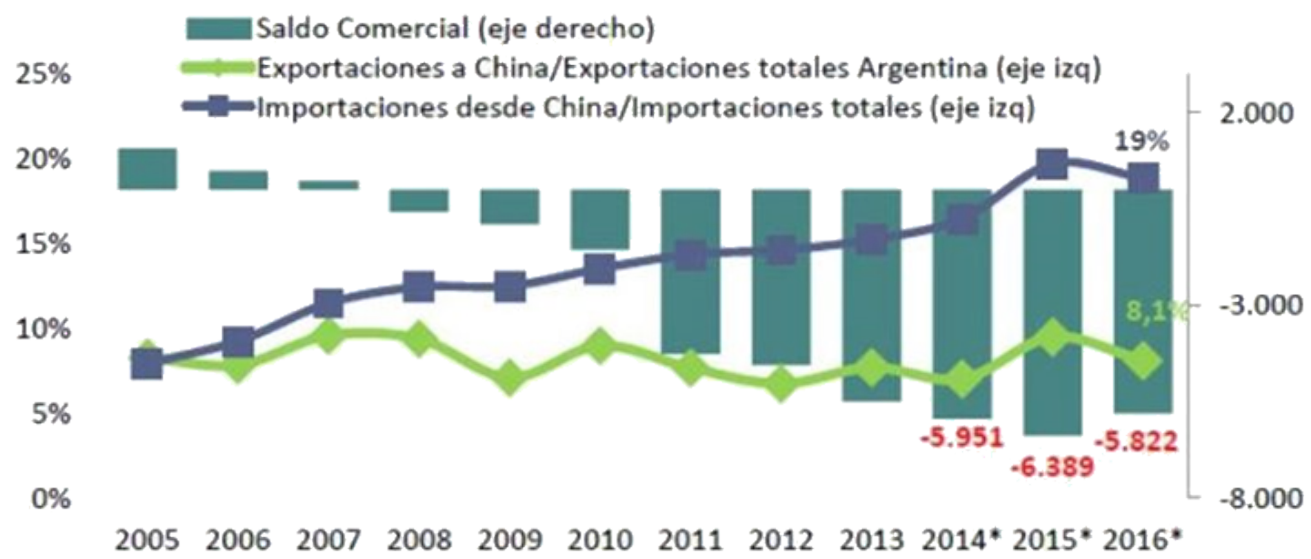

GRÁFICO 2: Participación de China en las exportaciones e importaciones argentinas y saldo comercial (millones de dólares)

(Fuente: Salvador, 2017)

El $92 \%$ de las exportaciones argentinas a China son agroindustriales. China es el segundo destino, detrás de la Unión Europea. En 2018 exportó a China bienes agroindustriales por US\$ 2,947 millones, según la Bolsa de Comercio de Rosario. Ver productos en Gráfico 3 y Tabla 3.

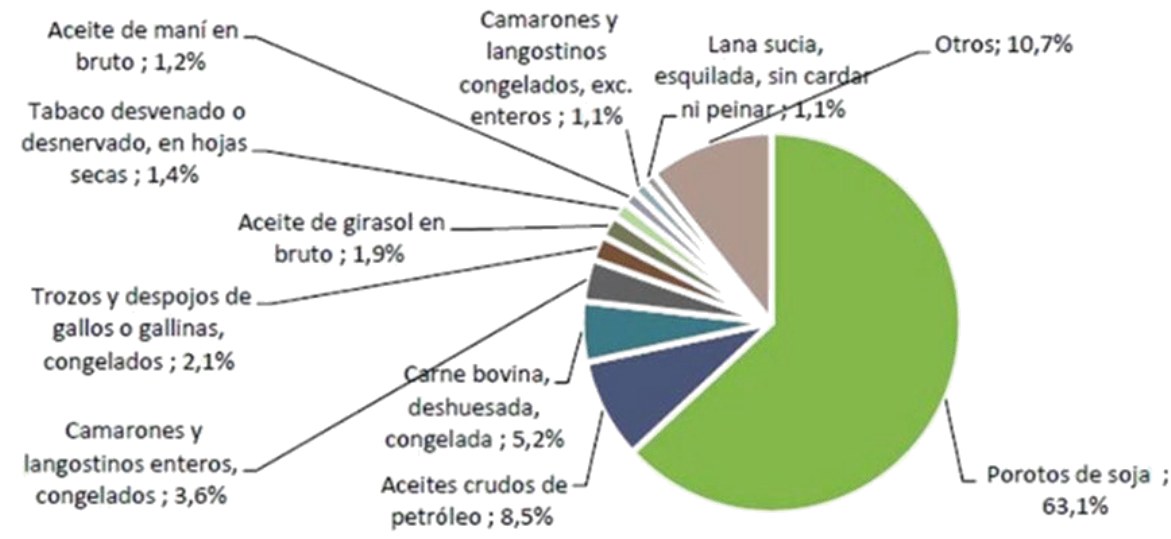




\begin{tabular}{|c|c|c|}
\hline Productos & Importaciones de China & Exportaciones de Argentina \\
\hline Autos, motor de émbolos y cilindrada $1.500-3.000 \mathrm{~cm}^{3}$ & 35.4333 & 557 \\
\hline Minerales de cobre y sus concentrados & 20.569 & 1.138 \\
\hline Cajas de cambio & II. 404 & 463 \\
\hline Demás medicamentos envasados & $9.75^{1}$ & 491 \\
\hline Aceites medios y preparaciones de petróleo & 7.652 & 10.820 \\
\hline Polietileno en formas primarias & 5.996 & 157 \\
\hline Propano, licuado & 4.397 & 234 \\
\hline Polímeros de etileno, en formas primarias & 4.139 & 183 \\
\hline Aceites ligeros y preparaciones de petróleo & 3.478 & 6.030 \\
\hline Butanos, licuados & I.685 & I86 \\
\hline
\end{tabular}

\section{EVOLUCIÓN DE LAS RELACIONES ECONÓMICAS ENTRE CHINA Y AMÉRICA LATINA Y LA INTERPRETACIÓN PREBISCH-CEPAL SOBRE EL DESARROLLO}

China consolidó una relación de subordinación económica con la región porque su modelo de producción estimuló el crecimiento del resto de las economías del mundo a través de la creación de un circuito virtuoso de inversión, producción y mercado, con impacto a escala global. En el contexto de la economía-mundo capitalista, América Latina fue arrastrada por ese centro dinámico (Oviedo, 2014) China se transformó en un país económicamente indispensable para la mayoría de los países: flujos de comercio, inversiones y préstamos. Es el principal socio comercial de Brasil, Chile, Venezuela, Perú, Uruguay y Argentina (desde septiembre de 20r9); segundo socio de Colombia y principal exportador a Paraguay y Bolivia. Alcanzó esta posición en menos de treinta años (Oviedo, 2012, 2017; Li, 20I2; Bernal-Meza, 2012; Sevares, 2015; Dussel, 2016; Moneta y Cesarín, 2016, Bernal-Meza and Li, 2020), especializando a nuestra región como una exportadora de productos primarios y commodities e importadora de sus bienes industriales, equipamiento, tecnologías, inversiones y préstamos. Siguiendo a esos autores, tenemos una interpretación coincidente en un período de diez años, que corresponde al espacio temporal en el que se han publicado estas investigaciones. La presencia económica de China comenzó a mediados de 1990 y se profundizó aceleradamente desde principios de 200o. Fue el resultado de lo que Oviedo (20I2) llamó la "lucha por la modernización". Es decir, la confrontación entre el modelo de desarrollo chino -industrialización orientada a la exportación- y el modelo latinoamericano industrialización por sustitución de importaciones- cuyo objetivo era el desarrollo de una industria destinada a satisfacer la demanda interna de bienes industriales para consumo de los 
mercados locales, bajo estructuras arancelarias y de políticas estatales proteccionistas (préstamos, provisión de divisas a precios subvaluados, regulación de las importaciones, etc.). En ese proceso, dado el éxito del modelo chino y el fracaso latinoamericano (Li, 2019; Bernal-Meza, 2019), China construyó una estructura que ha evolucionado bajo la clásica morfología centro-periferia interpretada por Prebisch (1949, 1951). La teoría del deterioro de los términos de intercambio, formulada en 1950, explica el fenómeno actual de las relaciones entre China y América Latina; poniendo en evidencia un acelerado proceso de re-primerización y primerización que conduce a una nueva etapa de dependencia, reproduciendo los ciclos de subordinación económica, con implicancias políticas, que nuestra región vivió con otras potencias hegemónicas en el pasado.

Como argumentó Bernal-Meza (2017: 77-79), el pensamiento chino ha intentado refutar la teoría del Deterioro de los Términos de Intercambio, dado que la crítica latinoamericana a la estructura de relaciones económicas chino-latinoamericanas construida por Beijing desde I99o sostiene que esta reproduce el clásico patrón centro-periferia. Jiāng Shíxué (2006), defendiendo la posición de China, afirmó que la relación comercial chino-latinoamericana se basaba en una cooperación ganadores-ganadores, gracias a que la demanda china de productos primarios o commodities había provocado un aumento de sus precios internacionales, mientras que la exportación de sus productos industriales, cuya producción era más barata que los similares exportados por otras economías industrializadas hacía que estos bienes llegaran más baratos a los mercados latinoamericanos. En conclusión, la balanza comercial resultaba favorable para los países latinoamericanos, lo que refutaba la tesis de Prebisch. El intercambio se ajustó a lo señalado por Jiāng hasta 2008, gracias al alza de los precios internacionales de bienes primarios, cuando China no alcanzaba aún la posición de primacía en el comercio exterior latinoamericano que detentaría después. Lo que ocurrió a partir de 2008 y el caso argentino pasó a ser el ejemplo más evidente (Oviedo, 2016; Sevares, 2015) fue que la demanda china de commodities comenzó a caer y retornó la tendencia decreciente de sus precios internacionales: comenzaron a encarecerse las importaciones, lo cual reafirmó la vigencia de la tesis de Prebisch acerca de la volatilidad de las exportaciones y de los precios de estos commodities. La realidad de la crisis internacional de zorz se reflejó en una baja de sus precios, con el consiguiente deterioro del sector exportador primario (Sevares 2015), lo que marcaría el fin del ciclo de oro de las materias primas (200I-2013). Con la excepción de Brasil, Venezuela, Chile y Perú, la balanza comercial bilateral con China pasó a ser enormemente deficitaria, además, por el impacto de México, cuyo déficit comercial equivale a dos tercios del déficit de todos los países de la región (CEPAL, 20I8: 40). Como sucedió en otras épocas de boom de las exportaciones primarias traccionadas por una economía industrial dinámica (etapas de 
dominación industrial de Gran Bretaña y de Estados Unidos, sucesivamente), China fue la gran locomotora del crecimiento económico latinoamericano por vía de la demanda de importaciones primarias. Pero esas exportaciones, desde 2014, cayeron más que las exportaciones al mundo. Según CEPAL (2015: 35), la caída de 2014 fue generalizada por la reducción de la demanda China. Sin embargo, aumentaron las importaciones industriales y crecieron los préstamos e inversiones chinos (Oviedo, 20r6; Sevares, 2016). CEPAL sostiene que "la caída del valor de las exportaciones de la región a China entre 2013 y 2016 también fue del 25\% y equivalió a más del doble de la contracción registrada por las importaciones regionales desde ese país (II\%)". Esto se explica en gran medida por el fin del denominado "superciclo" de las materias primas. La relación comercial es persistentemente deficitaria para la región y el déficit proyectado para 2017 fue cercano a los US\$ 67.0oo. Como señala CEPAL (2018:95)

Con la fuerte expansión observada en 2017, el comercio entre América Latina y el Caribe y China parece haber recuperado el extraordinario dinamismo que exhibió entre zooo y 2013, período en que su valor se multiplicó por 22. Sin embargo, las considerables carencias que presenta la relación comercial no muestran signos de atenuarse. Por una parte, el comercio es persistentemente deficitario para la gran mayoría de los países de la región; por otra, parte, es un intercambio netamente inter-industrial, en el que la región exporta de manera casi exclusiva recursos naturales (sobre todo en forma no procesada) e importa una amplia gama de manufacturas [...] El marcado déficit con China en el comercio de manufacturas sigue siendo fuente de preocupación en la región [...] El comercio, pese a su innegable potencial, ha contribuido poco al proceso de diversificación productiva y exportadora que la región requiere para alcanzar un desarrollo sostenible.

La síntesis de la relación bilateral es que los países latinoamericanos siguen inmersos en una estructura económica inter-industrial con China, producto de la diferencia en las dotaciones de los respectivos factores productivos.

Los académicos se refieren a las relaciones entre China y América Latina como relaciones Sur-Sur o Este-Sur, también como relaciones entre semi-periferia y periferia; o relaciones entre semi-periferia y semi-periferia (Pieterse, 2017; Li y Christensen, 2012). Una creciente literatura se centra en el análisis del surgimiento y evolución de estas relaciones (Bernal-Meza and Li, 2020; Pastrana y Gehring, 20I7; Oviedo, 2016; 2014, 20I2; CEPAL, 20I8, 2015; Medeiros y Cintra, 2015; Li and Christensen, 20I2; Li, 20I2, 20IO; Sevares, 2012). Estos autores coinciden en que entre ambas partes se ha desarrollado una estructura económica que ha hecho de la región latinoamericana la parte dependiente y subordinada de una relación que para América Latina se ha transformado en imprescindible. Paradojalmente, también complementaria y armoniosa, porque cada parte de la relación exporta a la otra aquello que constituye su canasta especializada de producción. 
En el aspecto político, China no demuestra estar interesada en apoyar la autonomía de la región en el ámbito de las relaciones hemisféricas y no pretende ser una alternativa a las relaciones entre Estados Unidos y América Latina. A pesar de participar de distintos organismos regionalismo, hemisféricos, regionales y subregionales -observador de OEA, BID, ALADI y Alianza del Pacífico-y ser el socio del foro CELAC, China no ha demostrado tener interés en presentarse como un actor que apoye la autonomía política de América Latina. China tiene preferencia por relaciones económicas bilaterales, privilegiando más unas que otras (Legler, Turzi y Tzili, 2020; Tzili, 2017; Ferrando, 2016) y el foro CELAC-China no representa ninguna amenaza a los principios ordenadores de las organizaciones hemisféricas (Tzili, 2017: 146).

China se ha transformado en el principal destructor de los procesos de integración, en particular del Mercosur (Hiratura, 2016; Bekerman y Moncaut, 20ı6; Oviedo, 2016; Bernal-Meza, 2012), por dos efectos: el deterioro de los términos de intercambio y la primarización y la reprimarización de las economías, porque esa especialización impide la modernización productiva y reduce el potencial exportador industrial. Efecto no deseado ha sido el desplazamiento de Brasil como eje dinámico de los procesos de integración económica (MERCOSUR) y política (UNASUR).

Tres elementos sustentan la relación centro-periferia. I) la armonía de intereses, entre las exportaciones latinoamericanas basadas en productos primarios y la importación de bienes de capital y manufacturas chinas; 2) la complementariedad comercial y financiera, derivada de una interdependencia comercial asimétrica y una dependencia de las fuentes chinas de provisión financiera; 3) la transformación de América Latina en una función del desarrollo económico chino, gracias a la complementariedad y armonía de intereses económicos y comerciales (Bernal-Meza, 2019; 2012; Oviedo, 2016; 2014); pero también en términos de beneficios políticos, en la medida que los países latinoamericanos apoyaron internacionalmente la agenda de intereses chinos: política de una sola China (Taiwan); no cuestionamiento a la ocupación del Tíbet ni a la violación de los derechos humanos del poder político chino; aceptación de China como una economía de mercado y apoyando su ingreso a la OMC (Bernal-Meza, 20I7; 20I2). Los dos primeros elementos se explican por la complementariedad y la interdependencia económica asimétrica. El tercero se explica, económicamente, por el papel que América Latina juega en el desarrollo económico e industrial chino; políticamente, porque América Latina adoptó la agenda de intereses políticos chinos. 


\section{IMPACTOS DE LA RELACIÓN BILATERAL SOBRE EL DESARROLLO} ECONÓMICO LATINOAMERICANO

La matriz del comercio, pese a su innegable potencial, ha contribuido poco al proceso de diversificación productiva y exportadora que la región requiere para alcanzar un desarrollo sostenible (CEPAL, 20I8: 95). En el afán de incrementar el potencial que evidenciaba este comercio exportador, a comienzos del siglo XXI, los países latinoamericanos, comenzando por Chile, tomaron decisiones políticas favorables a China. Respaldaron sus objetivos económicos y políticos. El apoyo para su ingreso en la OMC se convirtió en un factor negativo. Desde que China ingresó, hasta el año anterior a la crisis financiera internacional (2008), las exportaciones chinas a la región aumentaron un $34 \%$, pero las exportaciones no lo hicieron.

La sinergia de los factores internos - relaciones Estado-mercado-sociedad-y factores externos - geopolíticas, relaciones geoeconómicas en un contexto sistémico- llegó a configurar las estrategias de desarrollo china y de América Latina en diferentes direcciones. El éxito chino permitió articular su desarrollo y economía con el mercado global: captación de inversión extranjera, cadenas de producción, cadena de valor. Ese éxito puso de manifiesto el fracaso de las políticas de modernización e industrialización seguidas por América Latina. Las economías latinoamericanas comenzaron a verse arrastradas por la dinámica del comercio exterior del centro propulsor, que estaba creando dependencia en las economías subdesarrolladas (Oviedo, 2014: 151). Esta dinámica se profundizó cuando China se convirtió en el eje del dinamismo económico mundial y comenzó a desplazar a otras economías industrializadas de ese lugar: en la Unión Europea a Alemania y Francia, en Asia a Japón y Corea del Sur y compitiendo con Estados Unidos en la economía mundial. La razón de la relación dependiente, armoniosa y cada vez más importante, entre nuestra región y China, ha sido el extraordinario crecimiento económico chino y la diferencia en el nivel de desarrollo científico y tecnológico favorable a China, que la convirtió en un país cada vez más relevante para las relaciones económicas internacionales de exportación e importación y las ofertas de inversión. Gracias a esta diferencia en los niveles de desarrollo científico y tecnológico en el sector industrial, el avance de las exportaciones primarias latinoamericanas a China coincidió con el aumento de las exportaciones industriales chinas. Comparativamente, hace treinta años, Brasil tenía una inserción económica mayor que China en la 
economía mundial y sus exportaciones industriales superaban con creces las exportaciones industriales chinas. A partir del año zooo la realidad sería la opuesta ${ }^{5}$.

China introdujo un factor de profundo desequilibrio en la región y en el papel que desempeñaba Brasil en América del Sur (Dussel, 2or6; Medeiros e Cintra, 2015; Bernal-Meza, 2or6; 2012) al convertirse en un actor clave de la economía política internacional de América del Sur, desplazando a la potencia regional.

La confrontación de modelos de modernización socioeconómica, entre los ejemplos chino y latinoamericano es la otra cara de la moneda del éxito de la inserción económica internacional china y también del fracaso latinoamericano. Sus democracias no lograron transformar las estructuras productivas; no diversificaron las exportaciones, no disminuyeron la pobreza ni redujeron la profunda desigualdad en la distribución de la riqueza interna. Los gobiernos populares o de izquierda no supieron aprovechar el boom de las exportaciones de commodities para promover una reestructuración dinámica de sus estructuras productivas e industriales y buscaron sacar provecho de los ingresos por exportaciones destinando los recursos a objetivos de políticas públicas que no estuvieron destinadas a la modernización (Oviedo, 20I2), para enfrentar las cadenas de valor de Asia. Cuanto más dependiente es América Latina de las importaciones chinas y sus exportaciones de capital, más comprometida está la región en su autonomía económica y financiera internacional.

\section{EL PAPEL DE LAS INVERSIONES Y DIVERSIFICACIÓN PRODUCTIVA}

La IED ha jugado un papel importante en el desarrollo económico de la región. El inicio del proceso de inversión hacia la región coincidió con el "Libro Blanco para América Latina" de 2008, que respaldó el argumento de que las estrategias de inversión en América Latina fueron decisiones políticas (Oviedo, 2017, Sevares, 2016). Desde 2007-2008, China se convirtió en la segunda fuente de inversión extranjera para la región y un proveedor de financiamiento a través de diferentes mecanismos de préstamos. Los proyectos de infraestructura "llave en mano" proporcionados por las empresas chinas pasaron a ser importantes instrumentos para proveer tecnología, financiamiento, mano de obra china, mantenimiento y procesos de postventa. Sin embargo, la IED china se ha concentrado en proyectos y adquisiciones en sectores intensivos en recursos naturales (minería, petróleo y gas), aunque en los últimos cinco años se dirige crecientemente a las telecomunicaciones,

${ }^{5}$ ver hetps://cutt.ly/pmP Gsqr 
la industria automotriz y las energías no convencionales. Según la CEPAL (2018: 96), estos tres sectores ofrecen oportunidades atractivas a las empresas chinas y pueden desempeñar un papel relevante en el desarrollo de América Latina y el Caribe. No obstante, en el balance, las inversiones y los préstamos han sido clave en el proceso de re-periferización de las economías industriales de la región, tales Brasil y Argentina.

La IED china presenta una condición contradictoria. No tiene vínculos con la estructura productiva y social de los países latinoamericanos y del Caribe (Ortíz y Dussel, 2or6:I8; BernalMeza, 20I2). Paradójicamente, la cantidad y calidad de la inversión extranjera directa (OFDI) de China, a pesar de ser la región el segundo destino de exportación de capital, los tratados de inversión no promueven la OFDI de China en la región (Liss, 2018). Citando a Lin (2015: II), concluyó que la OFDI "demuestra la intención de las empresas estatales chinas de obtener fuentes de petróleo y recursos minerales en América Latina y el Caribe". Otros analistas concluyen que las empresas estatales chinas no tienen motivación comercial para invertir, sino que tratan de aplicar la estrategia de desarrollo a largo plazo (Liss, 20ı8: 9-то).

La IED se ha incrementado notablemente en los últimos diez años, aunque sigue concentrada en pocos países (CEPAL, 2018). La expansión obedece a una estrategia económica y política del gobierno chino (Bernal-Meza y Li, 2020; CEPAL, 2018; Oviedo 2017; Sevares, 2015). Oviedo (2017:I6), señaló que el 50,4\% de las IED chinas es realizada por Empresas de Propiedad Estatal; mientras que el restante $49,6 \%$ es a través de otras formas de empresas. Entre estas, las Sociedades de Responsabilidad Limitada (32,2\%) y las Compañías Limitadas Accionarias (8,7\%). Según CEPAL (2018:22)

Si bien la información oficial disponible de los bancos de desarrollo de China no es lo suficientemente detallada para obtener en cada caso la desagregación de los montos financiados por país, sector y proyecto, se estima que el monto de los compromisos de préstamos a los Gobiernos de América Latina y el Caribe financiados por China en el período 2005-2016 asciende a un total superior a US\$ I41.00o millones.

Esta cifra es superior a la que otorgaron el BID, el Banco Mundial y el Banco de Desarrollo de América Latina. Pero ese financiamiento está muy especializado por sectores. "Los bancos chinos dirigen más de la mitad del monto total de sus préstamos a la infraestructura; casi un tercio a la extracción de hidrocarburos y la distribución y generación de energía, y el resto a financiamiento del comercio, apoyo presupuestario y otros proyectos mixtos" (CEPAL, 2018: 23). Entre 2005 y 2016 ingresaron cerca de US\$90.0oo millones; lo que representó el 5\% de la IED recibida por América Latina y el Caribe. Sin embargo, la información disponible hace suponer que es probable que en 
2017 se haya producido un incremento muy marcado tanto de los montos absolutos, como de la participación china en la IED que recibe la región. Para la CEPAL (2018, p. 56), es posible estimar en más de US\$25.0oo millones la inversión realizada por las empresas chinas en 2017. Ver Gráfico 4.

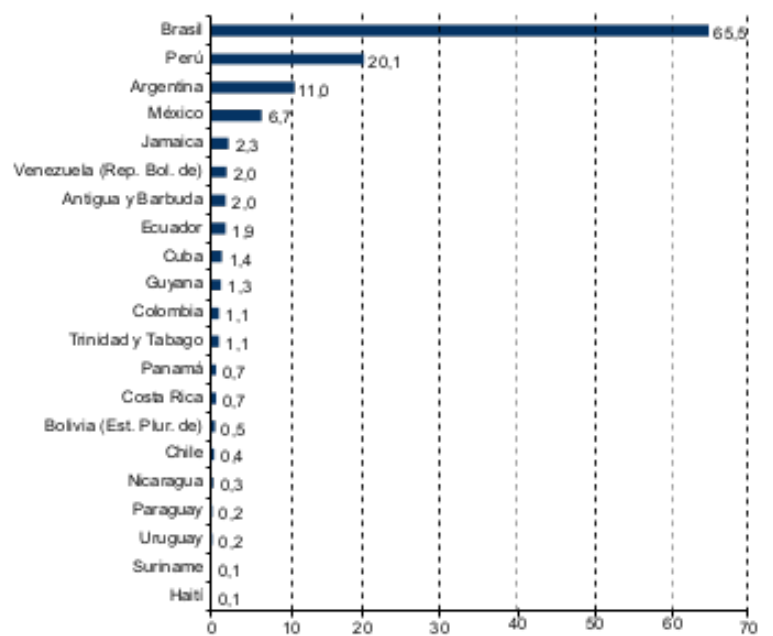

GRÁFICO 4: América Latina y el Caribe (21 países): estimación de las entradas de inversión extranjera directa (IED) desde China. por país de destino, 2005-octubre de 2017 (En millones de dólares y porcentajes) (Fuente: CEPAL, 20I8, p. 57)

Sin embargo, Oviedo (2017) en su investigación, concluyó que: I) la exportación de IED china a América Latina y Caribe está concentradas en "paraísos fiscales", por lo tanto, no se sabe si el destino final de esas inversiones corresponden o no a países de ALC; 2) estas inversiones son directas, o por lo menos deben ser consideradas directas, solo en esos paraísos fiscales; 3 ) hay mayor inversión china en países del Mercosur que en países de la Alianza del Pacífico; 4 ) el gobierno chino asigna a la inversión un alto contenido de decisión política más que prestar atención a las condiciones macro-económicas del país receptor; 5) preferencia china a firmar acuerdos bilaterales para realizar proyectos de infraestructura (represas, ferrocarriles, minería, etc.). Sevares (2015), ya había señalado que las inversiones y préstamos se orientaban principalmente al desarrollo y financiamiento de actividades primarias. Oviedo (2017) presenta datos estadísticos: Ver Tabla 4. 
TABLA 4: Flujo de IED chinas hacia América Latina y Asia. 2005-2015 (millones de dólares).

\begin{tabular}{|c|c|c|c|c|c|c|c|c|c|c|c|}
\hline & 2005 & 2006 & 2007 & 2008 & 2009 & 2010 & $20 I I$ & 2012 & 2013 & 2014 & 2015 \\
\hline Global & I2.26I & 16.733 & 26.506 & 55.907 & 56.528 & $68.8 \mathrm{II}$ & 74.654 & 87.803 & 107.840 & I23.120 & 145.667 \\
\hline ALC & 6.466 & 8.468 & 4.902 & 3.677 & $7 \cdot 327$ & I0. 538 & II. 935 & 6.169 & I $4.35^{8}$ & I0.540 & $\mathrm{I} 2.6 \mathrm{IO}$ \\
\hline Argentina & o & 6 & 136 & 108 & -22 & 27 & I85 & 743 & $22 \mathrm{I}$ & 270 & 208 \\
\hline Brasil & 15 & IO & $5^{\mathrm{I}}$ & 22 & II 6 & 487 & 126 & 194 & $3 \mathrm{IO}$ & 720 & -63 \\
\hline Venezuela & 7 & I8 & 69 & 9 & II5 & 94 & 8I & I. $54 \mathrm{I}$ & 425 & 249 & 288 \\
\hline Paraguay & & & - & 3 & 6 & 27 & 5 & I & $\mathrm{O}$ & - & - \\
\hline Uruguay & & & $\mathrm{o}$ & - & 5 & $\mathrm{o}$ & $\mathrm{o}$ & 9 & 9 & I & 36 \\
\hline Colombia & & & $\mathrm{o}$ & 7 & 6 & 7 & 33 & 83 & I7 & 183 & 4 \\
\hline Chile & & & 3 & 0,9 & 7 & 33 & I3 & 26 & II & 16 & 6 \\
\hline México & & & 17 & 5 & 0,8 & 26 & $4 \mathrm{I}$ & 100 & 49 & I40 & -6 \\
\hline Perú & & & 6 & 24 & $5^{8}$ & I39 & $2 \mathrm{I} 4$ & -49 & II4 & 45 & -I77 \\
\hline Vírgenes & $\mathrm{I} .226$ & 538 & г. 876 & 2.IO4 & I.6I2 & 6.II9 & 6.208 & 2.239 & 3222 & $4.57^{\circ}$ & I. 849 \\
\hline Caimán & 5.162 & 7.832 & $2.60 \mathrm{OI}$ & I. 524 & 5.366 & 3.496 & 4.936 & 827 & 9253 & 4.190 & I.O2I \\
\hline ASIA & 4.484 & 7.663 & 16.593 & $43 \cdot 547$ & 40.407 & 44.890 & 45.494 & 64.784 & 75.604 & 84.990 & I08.370 \\
\hline $\begin{array}{l}\text { Hong } \\
\text { Kong }\end{array}$ & 3.419 & 6.930 & $13.73^{2}$ & 38.640 & 35.600 & 38.505 & 35.654 & $5^{1.238}$ & 62.823 & 78.700 & 89.798 \\
\hline
\end{tabular}

(Fuente: citado en Oviedo, 2017, p. 18)

\section{UNA EXPLICACIÓN ESTRUCTURAL PARA ESTA NUEVA ETAPA DEPENDENCIA DE AMÉRICA LATINA}

China se convirtió en actor central de la economía mundial porque su modelo de producción estimuló el crecimiento del resto de las economías del mundo a través de la creación de un circuito virtuoso de mercado, producción e inversión. Su presencia económica regional se extendió ampliamente desde principios de 200o. Fue el resultado de lo que Oviedo (20I2) llamó la "lucha por la modernización": la confrontación entre el modelo de desarrollo chino —exportación orientada a la exportación- y el modelo latinoamericano de industrialización por sustitución de 
importaciones; seguido más tarde por el fracaso del modelo de inserción por vía de la desregulación, el desmantelamiento de las industrias estatales, las privatizaciones de los bienes públicos y la apertura comercial unilateral, que fueron promovidas por las políticas neoliberales respaldadas por el Consenso de Washington, aplicados por la mayoría de los países sudamericanos y por México, a partir de los años de i99o.

Al analizar la evolución del PIB de las veinte principales economías del mundo, entre 1980 y 2000 se observa cómo China - también India y Corea del Sur- se elevan en el ranking mundial, mientras Brasil, México y Argentina retroceden. La economía de Brasil siempre había sido más grande que la de China hasta 1990, cuando esta superó a Brasil ${ }^{6}=$

El éxito de la modernización china, bajo un sistema político autoritario, puso de manifiesto el fracaso de los líderes latinoamericanos para promover, bajo sistemas políticos democráticos, exitosas modernizaciones económicas. La relación complementaria y armoniosa centro-periferia condujo a la especialización de ambas partes. Sería difícil probar que ello fuera el resultado de un objetivo político chino.

\section{CONCLUSIONES}

El extraordinario ascenso de China en la estructura de poder económico mundial, un hecho sin recedentes en la historia del capitalismo (Li, 2019; 2010; Li Minqi, 2008) impactó sobre la región latinoamericana que quedó a la cola del desarrollo científico-tecnológico e industrial. De acuerdo a Muchie y Li (2010:53) "China's emergence will, on the one hand, unavoidably generate power shift and shape the international order in new ways, but on the other hand help construct a new type of balance of power in world politics based on multilateralism and institutionalism". El hecho de pasar de la periferia al centro en menos de cuarenta años generó profundas transformaciones en las relaciones entre el centro, la semi-periferia y la periferia (Li, 20I2; 20I2a; Li and Christensen, 20I2). Ese movimiento hacia el centro modificó la jerarquía de posiciones en la estructura económica mundial y se transformó en una fuente potencial de conflictos con los países que van quedando rezagados en el proceso, en particular aquellos como Brasil y Argentina, que habían iniciado su industrialización en los años 1910-1920 y que hacia 1970 ya eran identificados internacionalmente como parte del segmento "semi-periférico" de la economía mundial (Arrighi, 1998; Wallerstein, 1979) sustituyendo sus producciones y mercados de exportación industriales. Esto fue señalado por

\footnotetext{
${ }^{6}$ ver https://cutt.ly/pmPGscr
} 
Li (2012;) y Li y Christensen (20I2a), quienes sostuvieron que se preveía que el ascenso económico de China y su presencia en las zonas de la semi-periferia, plantearía más retos y restricciones al desarrollo de los países más atrasados. Como señala Bernal-Meza (2020), los desafíos para los países periféricos y semi-periféricos derivan de las consecuencias de la exitosa modernización china. Lamentablemente para la región, "las características que presenta el comercio entre la región y China son difícilmente modificables en plazos breves. Su carácter inter-industrial es el resultado principalmente de la complementariedad entre las respectivas dotaciones actuales de factores productivos" (CEPAL, 2017: 95).

El origen, desarrollo y profundización de la relación centro-periferia tiene dos causas. Primero, la enorme diferencia en el desarrollo científico-tecnológico que China ha acumulado. Segundo, la gran brecha de productividad: muy alta en China y muy baja en toda América Latina. En conclusión, siete argumentos permiten sostener el diagnóstico complejo acerca del carácter de la relación bilateral chino-latinoamericana:

I. No hay razón para decir que políticamente China representa para América Latina una alternativa de autonomía política y económica respecto de Estados Unidos. Más allá de que China haya asociado a Brasil a su agenda de intereses en la cooperación sur-sur y en el marco de BRICS (Bernal-Meza, 2019), ni Brasil ni otros países de la región han sido asociados por China a sus estrategias internacionales en relación a los temas de la política mundial: seguridad estratégica; conflictos regionales; reforma y ampliación del Consejo de Seguridad, etc. Pero la búsqueda china de primacía económica mundial ha hecho que América Latina desempeñe un papel importante en su estrategia internacional. Como señalan Moneta y Cesarín (2016), los objetivos chinos en la región convergen con sus aspiraciones globales como un poder creciente; la voluntad de proyectar el poder hacia la periferia estadounidense y acceder a los recursos naturales esenciales para sostener su crecimiento económico.

2. Las relaciones políticas de China con América Latina siguen un patrón de pragmatismo y juegan según los intereses económicos chinos.

3. Tanto el comercio como las inversiones están en relación con los intereses nacionales chinos, en el sentido que proporcionan seguridad alimentaria, insumos básicos, comunicación estratégica, y acceso al transporte (Oviedo, 2016; Sevares, 2015).

4. América Latina desempeña un papel importante en la estrategia capitalista global china a través de la especialización productiva y el comercio inter-industrial. 
5. China tiene impactos negativos en los procesos de integración de América Latina, en particular del Mercosur, al sustituir los flujos comerciales y estimular la especialización. Este fenómeno desagrega la relación económica internacional de los países sudamericanos y los aleja entre sí, debido a la falta de complementariedad y al aumento de la competencia productiva entre sí.

6. La complementariedad comercial y la armonía del intercambio no contribuyen al desarrollo y la modernización productiva e industrial de los países de la región, ya que ambos se producen en relación con un actor externo a la región que fortalece la especialización productiva.

7. A través del comercio, las inversiones y los préstamos, existe el riesgo que los gobiernos de algunos países latinoamericanos sufran presiones del Estado chino, como se ha observado en las dos economías más industrializadas: Brasil, a través de las inversiones chinas en el sector eléctrico (Becard, et. al, 2019), segmento económicamente estratégico y en el caso de Argentina, a través de la negociación de acuerdos con la inclusión de la cláusula del cross default, que determina que una vez negociados los términos de un contrato que incluye varios proyectos, la revisión de uno de ellos pondrá fin a todos ellos. De esta forma, se ata toda la red de acuerdos negociados entre China y Argentina (Bernal-Meza y Zanabria, 2020). Este mecanismo ha impedido a la Argentina renegociar con éxito las condiciones de los acuerdos firmados con Beijing bajo los gobiernos de Cristina Fernández, cuyas condiciones han sido consideradas muy beneficiosas para China, pero no para Argentina (Bernal-Meza y Zanabria, 2020; Oviedo, 2016; Sevares, 2015).

La fortaleza acumulada por China en la economía mundial durante los últimos cuarenta años se ha traducido en una "consecuencia no deseada" para otros países, como América Latina. Tal vez no fuera el "plan original" de China convertirla en su periferia. Es el resultado de la estrategia industrial elegida por China la que ha creado una consecuencia involuntaria para otros países, tanto del Norte como del Sur, porque esas relaciones están impulsadas por la ley del valor y la lógica económica del capitalismo. No parece haber un proceso colonial entre China y América Latina, a pesar de que algunas características históricas se repitan pues existe subordinación y dependencia económica y financiera.

Factores de fortaleza que subrayan el auge económico chino también son expresión de las debilidades de los países de la región. La contracara del éxito chino es el fracaso de América Latina, pues al amparo y la protección del modelo de industrialización por sustitución de importaciones, 
ni el sector privado que se benefició de los mercados cautivos, ni el Estado, que no impulsó su apoyo, ni las universidades, hicieron la necesaria inversión en ciencia y tecnología. El desarrollo tecnológico y la relación innovación-desarrollo no fueron una política pública ni del sector privado. La consecuencia fue la primerización y re-primerización económica. Este proceso ha sido acompañado por una muy eficiente y exitosa diplomacia china (Ferrando, 2or6; Rodríguez y Yan, 2013) basada en la win-win rhetoric de los principios de la cooperación Sur-Sur (Bernal-Meza; 2016).

América Latina debería poner atención no solo en la inversión, el comercio y la tecnología que comienzan a dominar ampliamente, sino en la "economía política" generada por el auge económico de China: cuáles son los efectos y consecuencias de la estructura de relacionamiento bilateral vis-à-vis las relaciones económicas y políticas internacionales de cada parte, en el marco de la evolución del sistema capitalista mundial.

China tuvo un plan que siguió durante 40 años para convertirse en lo que es. No vemos un ejemplo similar en ningún país latinoamericano. La naturaleza de la relación bilateral debe considerarse una consecuencia del análisis precedente. La posición alcanzada por China y el poder económico-científico-tecnológico que la sustenta ponen en evidencia el rotundo fracaso de las estrategias de desarrollo implementadas por América Latina.

\section{RECONOCIMIENTOS}

Investigación realizada en el Instituto de Estudios Internacionales (INTE), de la Universidad Arturo Prat.

\section{REFERENCIAS}

Arrighi, G. (1998). A Ilusão do desenvolvimento. Vozes.

Becard, D., y Silva, R. (2017). “China y Brasil: ¿modelo de relaciones Sur-Sur?”. En E Pastrana B. y H Ghering (Eds.), La proyección de China en América Latina y el Caribe (Págs. 387-408). Editorial Javeriana.

Becard, D., Barros-Platiau, A. y Lessa, A (2019), "Brazil in the BRICS after ten years". En X Li (Ed.), The International Political Economy of the BRICS (Págs. I35-I49). Routledge.

Becker, U. (Ed.). (2013). The BRICs and Emerging Economic in Comparative Perspective. Political Economy, Liberalization and International Change. Routledge.

Bekerman, M. y Moncaut, N (2016). "Las relaciones entre China y América Latina. ¿hacia la desestructuración de los sistemas productivos de la región?" En C Moneta y S Cesarín 
(Eds.) La tentación pragmática. China-Argentina/América Latina: Lo actual, lo próximo y lo distante (Págs. I85-202). Universidad Nacional de Tres de Febrero.

Bernal-Meza, R. and Li, X. (Eds.), (2020). China-Latin America Relations in the 21st Century: the Dual Complexities of Opportunities and Challenges. Palgrave Macmillan.

Bernal-Meza, R. (2019). Brazil as an emerging power: the impact of international and internal deteriorational effects on the BRICS. En X Li (Ed.), The International Political Economy of The BRICS (Págs. II8-I34). Routledge.

Bernal-Meza, R. (2017). Dos aportes teóricos latinoamericanos de relaciones internacionales y su utilización por el pensamiento chino contemporáneo: los casos de Prebisch y Escudé, Revista Estudios Sociales, 64, 75-87.

Bernal-Meza, R. (2016). China and Latin America Relations: The Win-Win Rhetoric, Journal of China and International Relations. Special issue, 27-43.

Bernal-Meza, R. (2014). La heterogeneidad de la imagen de China en la política exterior latinoamericana. Perspectivas para la concertación de políticas. Comentario Internacional, I4, II3-I34.

Bernal-Meza, R. (20I2). China y la configuración del nuevo orden internacional: las relaciones China-MERCOSUR y Chile. En R Bernal-Meza y S Quintanar (Eds), Regionalismo y Orden Mundial: Suramérica, Europa, China (Págs. 55-II4). Nuevohacer.

Bernal-Meza, R. (1996). La Globalización: ¿Un proceso y una ideología? Realidad Económica, i39, 8399 .

Bernal-Meza, R. and Zanabria, J. (2020). A goat's cycle. The relation between Argentina and the People's Republic of China during the Kirchner's and Macri administration (2003-2018). En R Bernal-Meza and X Li (Eds.), China-Latin America Relations in the 21st Century: the Dual Complexities of Opportunities and Challenges (Págs. III-I45). Palgrave Macmillan.

CEPAL. (2018). Explorando nuevos espacios de cooperación entre América Latina y el Caribe y China, LC/TS.2018/6. Naciones Unidas.

CEPAL. (2015). América Latina y el Caribe y China. Hacia una nueva era de cooperación económica. LC/L.4OIo. Naciones Unidas.

Dussel Peters, E. (Coord.). (2016). La nueva relación comercial de América Latina y el Caribe con China. ¿Integración o desintegración regional?. Red Académica de América Latina y el Caribe sobre China, Universidad Nacional Autónoma de México.

Ferrando, A. (2016). China y sus Tratados de Libre Comercio con América Latina y el Caribe. En C Moneta y S Cesarín (Eds.), La tentación pragmática. China-Argentina/América Latina: Lo actual, lo próximo y lo distante (Págs. 203-245). Universidad Nacional de Tres de Febrero.Hiratura, C. (2016). Impactos de China sobre el proceso de integración regional de Mercosur. En E Dussel Peters (Coord.), La nueva relación comercial de América Latina y el 
Caribe con China. ¿Integración o desintegración regional? (Págs. 195-243). Red Académica de América Latina y el Caribe sobre China, Universidad Nacional Autónoma de México.

Jiang, S. 2006. Recent Development of Sino-Latin American Relations and Its Implications. Estudios Internacionales, 152, 19-42.

Legler, T. Turzi, M. and Tzili, E. (2019). Advancing Autonomy? Chinese Influence on Regional Governance in Latin America. En R Bernal-Meza and X Li (Eds.), China-Latin America Relations in the 21st Century: the Dual Complexities of Opportunities and Challenges (Págs. 27-53). Palgrave Macmillan.

Li, M. (2008). The rise of China and the demise of the capitalist world economy. Monthly Review Pres.

Li, X. (2020). Revisiting China-Latin America Economic Relations: an unintended consequence of different industrialization strategies? En R Bernal-Meza and X Li (Eds.), China-Latin America Relations in the 21st Century: the Dual Complexities of Opportunities and Challenges (Págs. 225-25I). Palgrave Macmillan.

Li, X. (2019). China's dual position in the capitalist world order: a dual complexity of hegemony and counter-hegemony. En X Li (Ed.), The International Political Economy of The BRICS (Págs. 95-II7). Routledge.

Li, X. (2012). Introduction: The Unanticipated Fall and Rise of China and the Capitalist World System. En X Li and S Christensen (Eds.), The Rise of China. The Impact on Semi-periphery and Periphery Countries (Págs. I-29). Aalborg University Press.

Li, X. (20ro). The Rise of China and the Capitalist World Order (Ed.). Surrey: Ashgate.

Li, X. and Christensen, Steen F. [eds.], (2012). The Rise of China. The impact on semi-periphery and periphery countries, Aalborg: Aalborg University Press.

Li Xing and Shaw, T. (2013). From 'Polities in Command' to 'Economics in Command'; ChinaAfrica Relations in an era of Great Transformations. In: X Li with AO Farah (Eds). ChinaAfrica Relations in an Era of Great Transformations. (Págs. I-22). Ashgate.

Lin, Y. (2015). Firm Heterogeneity and Location Choice of Chinese firms in Latin America and the Caribbean: Corporate Ownership, Strategic Motives and Host Country Institutions. China Economic Review, 34, 274-292.

Liss, J. (2018). Tratados de inversión entre China y América Latina y la salida de inversión extranjera directa de China en la región: un análisis interdisciplinario. Centro de Estudios México-China, UNAM.

Medeiros, C. and Cintra, M (2015). Impacto da ascensão chinesa sobre os países latino-americanos. Revista de Economía Política, 35(I), 28-42.

Muchi, M. and Li X (2010). The myths and realities of the rising powers; is China a threat to the existing world order? En X Li (Ed.), The Rise of China and the Capitalist World Order (Págs. 5'-70). Ashgate. 
Ortiz, S. y Dussel, E. (2016). La nueva relación comercial entre América Latina y el Caribe y China: ¿promueve la integración o desintegración comercial? En E Dussel Peters (Coord.), La nueva relación comercial de América Latina y el Caribe con China. ¿Integración o desintegración regional? (Págs. 13-58). Red Académica de América Latina y el Caribe sobre China, Universidad Nacional Autónoma de México.

Oviedo, E. (2017). Alternancia política y capitales chinos en Argentina. En E Oviedo (Ed.), Inversiones de China, Corea y Japón en Argentina: análisis general y estudio de casos (Págs. I2-35). UNR Editora.

Oviedo, E. (2016). Défict comercial, desequilibrio financiero e inicio de la dependencia argentina del capital chino. En C Moneta y S Cesarín (Eds.), La tentación pragmática. ChinaArgentina/América Latina: Lo actual, lo próximo y lo distante (Págs. 273-298). Universidad Nacional de Tres de Febrero.

Oviedo, E. (20I2). Puja de modernizaciones y relaciones económicas chino-latinoamericanas en un mundo en crisis. En R Bernal-Meza y S Quintanar (Eds), Regionalismo y Orden Mundial: Suramérica, Europa, China (Págs. II5-I5I). Nuevohacer.

Pieterse, J. (2017). Multipolar Globalization: Emerging economies and Development. Routledge.

Polanyi, K. (1944/1957). The Great Transformation: The Political and Economic Origins of Our Time. Beacon Press.

Prebisch, R. (1949). El desarrollo de América Latina y algunos de sus principales problemas. CEPAL.

Prebisch, R. (1951). Problemas teóricos y prácticos del crecimiento económico. CEPAL.

Rodriguez, I. y Yan, S. [eds.]. (2013). La diplomacia pública de China en América Latina, RIL Editores.

Salvador, P. F. (2017). "Argentina-China: ¿Cómo es la relación comercial con el gigante asiático?", Cronista, I6/05/2017. https://cutt.ly/emGDlMB

Sevares, J. (2016). Préstamos e inversiones de China en América Latina. En C Moneta y S Cesarín (Eds.), La tentación pragmática. China-Argentina/América Latina: Lo actual, lo próximo y lo distante (Págs. 247-270). Universidad Nacional de Tres de Febrero.

Sevares, J. (2015). China. Un socio imperial para Argentina y América Latina. Edhasa.

Sevares, J. (2012). El ascenso de China y las oportunidades y desafíos para América Latina. En R Bernal-Meza y S Quintanar (Eds), Regionalismo y Orden Mundial: Suramérica, Europa, China (Págs. 325-344). Nuevohacer.

Tzili Apango, E. (2017). Antecedentes y proyecciones del Foro China-CELAC y su influencia en la dinámica hemisférica. En E Pastrana y H Gehring (Eds.), La proyección de China en América Latina y el Caribe (Págs. I45-169). Editorial Javeriana.

Wallerstein, I. (1979). The Capitalist World-Economy. Cambridge University Press. 